\title{
“WHO AM I AS A TEACHER?”: PROCESSOS ARGUMENTATIVOS NA EDUCAÇÃO INICIAL DO PROFESSOR DE LÍNGUA INGLESA POR MEIO DE BLOGS*
}

\author{
"WHO AM I AS A TEACHER?": ARGUMENTATIVE PROCESSES IN ENGLISH STUDENT-TEACHERS' \\ IDENTITY (RE)CONSTITUTION THROUGH THE LEARNING OF BLOG PRACTICES
"WHO AM I AS A TEACHER?": PROCESOS ARGUMENTATIVOS EN LA EDUCACIÓN INICIAL DEL PROFESOR DE LENGUA INGLESA POR MEDIO DE BLOGS

\author{
Lucas Moreira dos Anjos Santos** \\ Vera Lúcia Lopes Cristovão \\ Universidade Estadual de Londrina - UEL, Londrina, PR.
}

\begin{abstract}
RESUMO: Este artigo objetiva analisar os processos argumentativos mobilizados por alunas-professoras do curso de Letras Estrangeiras Modernas - Inglês na produção de uma postagem em blogs e suas relações com a sua (re)constituição identitária. Os dados analisados são provenientes da pesquisa de mestrado de um dos autores. Durante o ano letivo de 2010, alunas-professoras do terceiro ano frequentaram a disciplina optativa "Gêneros textuais e ensino de línguas estrangeiras" e produziram um blog como parte das atividades da referida disciplina. Os dados são analisados à luz dos procedimentos de análise textual do ISD (BRONCKART, 2003) e da Semântica Argumentativa (KOCH, 1997; OLIVEIRA, 2003; AZEVEDO; OLIVEIRA, 2005). As análises revelaram um processo de validação e consolidação do self das alunas-professoras, por meio da apropriação das práticas de uso do blog, desenrolado a partir de um movimento argumentativo que dá índices da (re)constituição identitária posta em curso pela intervenção feita.
\end{abstract}

PALAVRAS-CHAVE: blog; formação de professores; língua inglesa, argumentação.

ABSTRACT: This article aims at analyzing the argumentative processes mobilized by student-teachers from a Modern Foreign Language- English course when posting in blogs and their relations to identity (re)constitution. The data was gathered in an elective unit course and was part of one of the author's master research. During 2010, the student-teachers from 3rd year participated in the elective course named "Genres and Foreign Language Teaching" and produced their own blog as part of the required activities. The data are analyzed according to the textual analysis procedures of SDI (BRONCKART, 2003) and to Argumentative Semantics procedures (KOCH, 1997; OLIVEIRA, 2003; AZEVEDO; OLIVEIRA, 2005). The analysis revealed a process of validation and consolidation of the student-teachers selves, through the learning of blog practices, and the emergence of argumentative processes which highlight traces of identity (re)constitution.

KEYWORDS: blogs; teacher education; English language; argumentation.

RESUMEN: Este artículo objetiva analizar los procesos argumentativos movilizados por alumnas-profesoras del curso de Letras Extranjeras Modernas - Inglés en la producción de una publicación en blogs y sus relaciones con su (re)constitución de identidad. Los datos analizados provienen de la investigación de maestría de uno de los autores. Durante el año lectivo de 2010, alumnasprofesoras del tercero año asistieron la asignatura optativa "Géneros textuales y enseñanza de lenguas extranjeras" y crearon un blog como parte de las actividades de la referida asignatura. Los datos son analizados a la luz de los procedimientos de análisis textual del ISD (BRONCKART, 2003) y de la Semántica Argumentativa (KOCH, 1997; OLIVEIRA, 2003; AZEVEDO; OLIVEIRA, 2005). Los análisis revelaron un proceso de validación y consolidación del self de las alumnas-profesoras, por medio de la apropiación de las prácticas de uso del blog, desarrollado a partir de un movimiento argumentativo que da índices da (re)constitución de identidad puesta en curso pela intervención hecha.

PALABRAS-CLAVE: blog; formación de professores; lengua inglesa; argumentación.

\section{INTRODUÇÃO}

A adesão dos interlocutores às ideias de quem fala é uma condição essencial para o desenrolar do processo argumentativo. Sabemos, pois, que a retórica é estudada desde os tempos de Aristóteles e vem se transformando ao longo do tempo. (OLIVEIRA, 2002). Nesse sentido, compreendemos que a linguagem tem forte caráter persuasivo e argumentativo. As implicações de tal posicionamento para educação de

\footnotetext{
* Artigo fruto das discussões e reflexões realizadas na disciplina Semântica Argumentativa, ministrada pela professora Esther Gomes de Oliveira, no Programa de Pós-Graduação em Estudos da Linguagem da Universidade Estadual e Londrina - PR.

** Email: luca.dos.anjos@gmail.com.
} 
professores têm sido exploradas no âmbito do papel da argumentação na construção de conhecimentos e no processo reflexivo (LEITÃO, 2000; 2007).

Aderindo a tais pressupostos, e tendo por base, o quadro epistemológico do Interacionismo Sociodiscursivo (ISD, doravante), que considera as práticas humanas produtos de um processo de socialização no qual a linguagem desempenha papel fundamental, acreditamos poder ressignificar outras formas de produção de conhecimento e intervenção na educação de professores, tanto em nível inicial quanto continuada.

Para tanto, esse artigo objetiva analisar os processos argumentativos mobilizados por alunas-professoras do curso de Letras Estrangeiras Modernas - Inglês na produção de uma postagem em blogs e suas relações com a sua (re)constituição identitária.

Partimos da articulação das teses centrais do interacionismo sociodiscursivo e da argumentação. Apropriando-nos de outras vozes, buscamos ampliar o olhar para a linguagem, socio-historicamente construída, de tais vertentes. Passamos, então, a explicitar as características do blog e seu papel na educação de professores para uso da argumentação. Com base nesses pressupostos, apresentamos os dados e seu contex to de produção, analisamos as postagens, e tecemos considerações finais sobre a análise apresentada.

\section{ECOANDO OUTRAS VOZES: ARGUMENTAÇÃO NO PROJETO DO INTERACIONISMO SOCIODISCURSIVO}

O papel da linguagem na constituição do pensamento consciente é, amplamente, discutido por Vygostky (1992) ao analisar o papel da interiorização dos signos de linguagem na discretização e construção de representações mentais. Vygostky evidenciou o caráter social da atividade linguageira ao afirmar que o pensamento humano é constituído por meio das interações verbais nas quais nos engajamos.

Analogamente, Bakhtin (2006, p. 30) evidenciou o papel essencial das práticas sociais na produção linguageira ao afirmar que “(o) domínio do ideológico coincide com o domínio dos signos: são mutuamente correspondentes. Ali onde o signo se encontra, encontra-se também o ideológico. Tudo o que é ideológico possui um valor semiótico" (ênfase do autor). Já que o pensamento consciente humano é constituído a partir da interiorização da linguagem, tudo aquilo que pensamos advém do social.

Apropriando-se a ampliando as ideias desses referidos autores, o ISD entende que a linguagem não só constitui o pensamento humano consciente, como também regula e permite a realização de atividades gerais de socialização da espécie. Para tanto, Bronckart (2006, p. 79) afirma que o ISD admite:

(...) que a linguagem se constitui, de início, como uma prática ilocutória, fundadora da racionalidade social que rege as ações humanas. Esse prática se solidifica em sistemas de signos, ou línguas naturais, que permitem uma (re)codificação locutória particular (sociocultural) das representações racionais do mundo.

Decorre dessa concepção que a linguagem só existe nas práticas verbais nas quais é empregada e sua abstração em sistema de estruturas é posterior. A linguagem passa a ser entendida como processo ativo e criativo estabelecendo o acesso do indivíduo ao mundo. Ora, dada essa noção de linguagem como sóciohistoricamente construída e transformada/transformadora, que se concretiza única e exclusivamente na interação, é que o ISD recupera de Bakhtin (1992) a célebre máxima de que todo discurso se dirige a alguém e é uma resposta a outro alguém no elo da cadeia enunciativa.

Ao considerar a linguagem como agir (BRONCKART, 2008) podemos, então, estabelecer paralelos entre aquela e o papel da argumentação. Tal ideia não é desenvolvida pelos autores centrais do ISD, mas o faremos aqui, entendo sua compatibilidade com as teses centrais previamente apresentadas.

De qual argumentação falamos? Como bem aponta Koch toda ação linguageira pretende um efeito no seu interlocutor seja ele qual for. Se recuperarmos Bakhtin e a noção de dialogicidade do discurso também compreendemos que não existe prática verbal monológica. Sendo assim:

É por isso que se pode afirmar que o uso da linguagem é essencialmente argumentativo; pretendemos orientar os enunciados que produzimos no sentido de determinadas conclusões (com exclusão de outras). 
Em outras palavras, procuramos dotar nossos enunciados de determinada força argumentativa. (KOCH, 1997, p. 29).

Nessa perspectiva, partilhamos de uma concepção de argumentação na perspectiva enunciativa que confere a prática linguageira como sendo um espaço de embate de vozes. A produção de discursos visa à adesão dos interlocutores aos quais se dirigem.

Na concepção de Oliveira (2004, p. 123), a Semântica Argumentativa trabalha com a noção de que "a argumentação está na própria língua e somente a estrutura do enunciado não é o bastante para realizar, totalmente, o seu sentido; mecanismos diversos estão intrinsecamente ligados à própria semântica da língua”. Nesse sentido, a semântica argumentativa se preocupa em estudar as relações de contexto entre locutor e interlocutor e os procedimentos argumentativos postos em ação na produção linguageira para empreender uma determinada ação no mundo.

Acreditamos, ainda, que a argumentação tem papel decisivo na colocação em interface das representações individuais e coletivas de um indivíduo e pode ser produtora de novos sentidos a partir do processo cognitivo que gera. Liberali (2009) aponta que a argumentação pode ser entendida como uma ferramenta para superar visões de mundo autoritárias ou perspectivas dogmáticas do senso comum.

Nesse sentido, advogamos que a perspectiva de argumentação, aqui apresentada, é compatível com as teses centrais do ISD e pode favorecer a uma melhor compreensão do papel da linguagem como lugar de transformação das ações, como tem sido defendido por Bronckart (2008).

\section{PRODUZINDO OUTRAS SIGNIFICAÇÕES: O GÊNERO BLOG E SUA INTERFACE COM EDUCAÇÃO DE PROFESSORES E ARGUMENTAÇÃO}

O blog pode ser caracterizado como uma tecnologia digital cujo objetivo é compartilhar assuntos de interesse comum em uma comunidade virtual imaginada. Os blogs podem ser tanto relacionados à escrita sobre si quanto a escrita sobre assuntos que de alguma forma gerem adesão na sociedade. Como apontam Miller e Shepherd (2009, p. 75) “(o) que a maioria dos blogueiros acha mais atraente nos blogs é a habilidade de combinar o imediatamente real e o genuinamente pessoal." De certa forma, o blogueiro é sua própria audiência. É uma escrita de si para si mesmo. E é exatamente esse caráter autorreflexivo que justifica o uso desse gênero do meio virtual na educação de professores.

Em seus estudos sobre blogs, Miller e Shepherd (2009) entendem que essa tecnologia digital surge dentro de um contexto histórico em que as fronteiras entre o público e o privado têm se apagado. Além disso, aquilo que consideramos mundo real passa a ser constituído por um mundo virtual, um simulacro em que o virtual passa a ser real.

Os blogs surgem, originalmente, como uma forma de compartilhar interesses e a maioria dos blogueiros concorda que o mais importante nesse gênero é seu conteúdo. A própria organização do gênero blog, em forma inversamente cronológica, imprime a sensação de proximidade com seu interlocutor.

Diante disso, Miller e Shepherd (2009) reiteram que os blogs servem como ferramentas de consolidação e validação do self como uma resposta a um momento sociocultural de desestabilização das identidades dos indivíduos. Como defendem os autores, "o blog deve ser compreendido como uma reação particular ao constante fluxo de subjetividade, como uma tentativa genérica de reflexão dentro do sujeito que cria um redemoinho de relativa estabilidade.” (MILLER; SHEPHERD, 2009, p. 91)

Nesse sentido, o uso do blog com fins pedagógicos pode oportunizar “(...) infinitas possibilidades para o desenvolvimento da escrita, da capacidade argumentativa, da criatividade, da organização, da estética, proporciona experiência de aprendizagem colaborativa e permite a reflexão sobre valores éticos." (REIS, 2009, p. 106).

Dadas essas características do blog, que relações podemos estabelecer entre ele e educação de professores? Acreditamos, pois, que a apropriação de práticas de uso de blogs pode desencadear momentos de (re)construção identitária para o aluno-professor em educação inicial. Tal papel pode ainda ser acentuado se 
levarmos em conta que a produção linguageira é espaço de embate de vozes, conforme a perspectiva de argumentação previamente explicitada.

A argumentação, por meio do blog, pode gerar um confronto de vozes que constituem o indivíduo e induzir a problematizações sobre seu self. É por meio do saber-dizer propiciado pelo blog que pode se dar a inscrição do indivíduo em papéis que ele pode se ver ou não como profissional da linguagem. (MATENCIO, 2008).

\section{METODOLOGIA}

\subsection{Contexto de produção dos dados}

Os dados analisados, nesse artigo, são provenientes da pesquisa de mestrado de um dos autores. Durante o ano letivo de 2010, alunas-professoras do curso de Letras Estrangeiras Modernas - Inglês, cursando o terceiro ano, frequentaram a disciplina optativa "Gêneros textuais e ensino de línguas estrangeiras". Sua ementa pretendia contemplar: "Conceito de gêneros textuais. Questões epistemológicas e metodológicas. Objetivos e seleção de gêneros a serem ensinados. Transposição didática: as práticas sociais de linguagem como objeto de ensino." Para tanto, as alunas-professoras vivenciaram, enquanto aprendizes de línguas, uma abordagem baseada em gêneros ao mesmo tempo em que refletiram sobre as escolhas subjacentes a tal abordagem.

Ao longo do ano, as alunas-professoras produziram os seguintes gêneros digitais: fórum de discussão online, blog e chat educacional. A aprendizagem dos referidos gêneros se deu por meio do dispositivo de sequência didática cujo objetivo é permitir a apropriação das características do gênero por meio de atividades para mobilização das capacidades de linguagem necessárias à sua produção.

Enfocamos, para análise, um texto produzido dentro da sequência didática em torno de blogs. A produção foi orientada a partir das características já estudadas e tendo por base dois outros textos. Um deles era uma charge sobre os papéis assumidos pelo professor e outro era uma descrição sobre ser professor do ministério da educação de Singapura. Com bases nas vozes que eram ecoadas por esses textos, as alunas-professores foram orientadas a escrever uma nova postagem em seus blogs sobre "Quem sou enquanto professora?".

\subsection{Procedimentos de análise dos dados}

Os dados são analisados à luz dos procedimentos de análise textual do ISD (BRONCKART, 2003) e da Semântica Argumentativa (KOCH, 1997; OLIVEIRA, 2003; AZEVEDO; OLIVEIRA, 2005).

Partimos do levantamento do plano textual global de cada postagem. Então, identificamos as sequências que compõem os textos, e analisamos, por fim, os mecanismos linguístico-discursivos índices de argumentação.

\section{ANÁLISE DOS DADOS}

As postagens produzidas pelas alunas-professoras apresentam o seguinte plano textual global:

\begin{tabular}{|c|c|c|c|}
\hline $\begin{array}{l}\text { ALUNA- } \\
\text { PROFESSORA }\end{array}$ & $\begin{array}{l}N^{\circ} \text { DE } \\
\text { PALAVRAS }\end{array}$ & ORGANIZAÇÃO & CONTEÚDO TEMÁTICO \\
\hline Taylor & 267 & $\begin{array}{l}\text { Título: sentença } \\
\text { interrogativa } \\
\text { Corpo do texto } \\
\text { Assinatura }\end{array}$ & $\begin{array}{l}\text { Questionamento sobre quem sou como } \\
\text { professora. } \\
\text { Ser professora e mudança na vida dos } \\
\text { alunos. } \\
\text { (Re)pensar própria prática e conceitos sobre } \\
\text { o papel de um professor. } \\
\text { Características de um professor. } \\
\text { Avaliações de como alguns professores se } \\
\text { vêem }\end{array}$ \\
\hline $\mathrm{Ma}$ & 155 & $\begin{array}{l}\text { Título: sentença } \\
\text { interrogativa }\end{array}$ & $\begin{array}{l}\text { Projeção da professora que quer ser e não } \\
\text { da que é. }\end{array}$ \\
\hline
\end{tabular}




\begin{tabular}{|c|c|c|c|}
\hline & & Corpo do texto & $\begin{array}{l}\text { Dificuldades em ser professor. } \\
\text { Avaliação de como tem sido como } \\
\text { professora e seu papel. }\end{array}$ \\
\hline Joana & 345 & $\begin{array}{l}\text { Título: sentença } \\
\text { interrogativa } \\
\text { Corpo do texto }\end{array}$ & $\begin{array}{l}\text { Definição do que é ser professor. } \\
\text { Responsabilidades de um professor. } \\
\text { Exemplificação da responsabilidade de um } \\
\text { professor por meio da própria prática. } \\
\text { Definição do que tenta ser como professora. } \\
\text { Definição do que é ser professor. }\end{array}$ \\
\hline Libela & 220 & $\begin{array}{l}\text { Título: sentença } \\
\text { interrogativa } \\
\text { Corpo do texto }\end{array}$ & $\begin{array}{l}\text { Problemática em dizer que é como } \\
\text { professora. } \\
\text { Avaliação de como outras pessoas a vêem } \\
\text { como professora. } \\
\text { Projeção do que fazer para ser uma } \\
\text { professora melhor. }\end{array}$ \\
\hline
\end{tabular}

Tabela 1 - Plano Textual Global das Postagens. ${ }^{1}$

Taylor, a primeira aluna-professora, usa sequência argumentativa para defender que ser professor é um dom. Ela acredita não ter esse dom, logo não se vê como professora.

PREMISSA: não sei quem sou como professora porque tenho coisas a aprender.

ARGUMENTO 1 : as pessoas mudam de opinião

ARGUMENTO 2: professores precisam sempre estar bem

ARGUMENTO 3: professores que se vêem como tal tem o dom de ensinar

Por meio dessa produção de Taylor, é possível identificar que a aluna-professora se encontra num estágio de dúvida quanto a sua identidade profissional. Taylor mencionou várias vezes em sala de aula não querer ser professora. No entanto, nessa postagem, a aluna-professora faz um movimento que revela sua dubiedade. Ela diz já ter mudado um pouco sua visão sobre ensinar/aprender língua inglesa. Percebemos isso, pelo uso do operador argumentativo but que coloca em oposição duas ideias de Taylor: visão pessimista sobre ensino x visão mais otimista sobre ensino.

"When I started teaching, I had a pessimistic vision of all this, and I really though we couldn't change that much. But now I'm starting to think of my own practice and other's practices as well, and $i$ kind of saw that we can change something..."

A aluna-professora admite que mudou sua visão sobre ensino ao contrapor esses dois pontos de vista. Apesar desse primeiro movimento da aluna-professora em se admitir parcialmente como professora, logo em seguida ela traz três argumentos para dizer o que é ser professor: 1) ser professor é estar sempre bem; 2) ser professor é ter mente aberta e 3) ser professor é um dom. Ao fazer uso desses argumentos, a alunaprofessora parece se afastar de reconhecer-se como professora, conforme havia indicado anteriormente.

"I really admire the ones that say: I want to be a teacher for the rest of my life. You know, this ones look like they were born for it, as if they have been given a special commission. I'm not one of this, but I say good luck for them."

Novamente, fazendo uso do operador argumentativo but para indicar oposição, Taylor contrapõe: eu não nasci para ser professora x outras pessoas nasceram para ser professora. O ethos projetado por Taylor, nessa postagem de seu blog, parece revelar que a característica "público x privado" dessa tecnologia digital contribui para o movimento de dubiedade quanto a sua identidade profissional.

Ma, a segunda aluna-professora, faz o uso da sequência descritiva para apresentar a professora que deseja ser.

\footnotetext{
${ }^{1}$ A tabela 1 foi produzida como uma síntese dos dados que são analisados nesse trabalho. Para tanto, nos apoiamos no levantamento do plano textual global que consiste em "uma organização do conteúdo temático; mostra-se visível no processo de leitura e pode ser codificado em um resumo” (BRONCKART, 2003, p. 120).
} 
ANCORAGEM: o professor que quero ser

ASPECTUALIZAÇÃO 1: é difícil ser professor porque lidamos com pessoas

ASPECTUALIZAÇÃO 2: nova maneira de ensinar para lidar com essa dificuldade

RELACIONAMENTO: professor enquanto responsável pela educação dos alunos

Ma se vê parcialmente como professora. No entanto, ela avalia que não sabe a professora que é, e sim, a professora que gostaria de ser. Percebemos a oposição entre quem sou x quem quero ser por meio do operador argumentativo but e do uso do modalizador exactly.

"Now that I have just been introduced in this new world I have an opinion maybe no exactly about the teacher I am but about the teacher that I want to be"

Ma parte do pressuposto que trabalhar com pessoas é difícil, logo trabalhar como professor também o é. A aluna-professora faz uso o operador argumentativo all para amparar seu ponto de vista no senso comum. $\mathrm{O}$ uso do all lhe permite fazer uma afirmação plena sobre o assunto.

"We all know that work with people is not an easy think..."

Para tentar lidar com tal problema, Ma faz uso do dêitico temporal “in this moment”, para dar ideia de conjunção em relação ao tempo presente, e descreve o que tem tentado fazer, atribuindo outra característica ao que é ser professora. Ao fazer uso desse dêitico temporal, a aluna-professora reforça sua ideia primeira apresentada na ancoragem de que não é a professora que deseja ainda.

"In this moment I think that I am trying to introduce a new style of teaching, I am working with criticism and the student seemed enjoy this method."

Ma conclui sua postagem demonstrando que tem tentado ser a professora que deseja. Novamente faz uso de um dêitico temporal (now) que traz a ação para o momento conjunto de produção para dar continuidade a ideia de que essa é a professora que deseja ser. A aluna-professora ainda utiliza o operador argumentativo not only para indicar restrição acerca de que não quer ensinar somente língua para os alunos, mas também contribuir para sua formação educacional mais ampla.

"So now I think I am part of their education and not only responsible for teach them the language itself, but also all the habilities and knowledges that sorround my class"

Apesar de Ma se ver parcialmente como professora, a aluna-professora se demonstra insatisfeita. A postagem de Ma, em seu blog, parece evidenciar a ação social dessa tecnologia digital conforme apontada por Miller e Shepherd (2009). Ma age socialmente por meio do blog como um modo de validar seu self profissional e criar certo senso de estabilidade sobre quem deseja ser.

Já a aluna-professora Joana, faz uso da sequência argumentativa predominantemente para defender que ser professor é uma profissão maravilhosa. Ainda faz uso da sequência descritiva para elencar características de como é enquanto professora.

PREMISSA 1: ser professor é uma profissão maravilhosa

ARGUMENTO 1-1: o professor amplia horizontes

PREMISSA 2: ser professor é tornar o outro melhor

ARGUMENTO 2-1: o professor é responsável pelas vidas dos alunos

SITUAÇÃO INICIAL: descrição e apresentação da sua própria experiência enquanto professora.

COMPLICAÇÃO: necessidade de não ensinar somente inglês

ANCORAGEM: nova maneira de ensinar inglês

ASPECTUALIZAÇÃO: características dessa nova maneira de ensinar inglês

PREMISSA 3: a língua inglesa abre horizontes

CONCLUSÃO: ser professor é permitir outros modos de ser aos alunos

CONTRA-ARGUMENTO: ser professor na perspectiva apresentada é utopia.

Joana é a aluna-professora que menos se implica em sua postagem. A aluna-professora enfoca no que é ser professor de maneira genérica. Tal movimento de distanciamento, com suas exceções, parece indicar que 
Joana ainda não se vê como professora. Quando a aluna-professora se implica é para mostrar que aquele é seu ponto de vista. No exemplo a seguir, Joana faz uso do dêitico de pessoa "me" para evidenciar essa relação:

"Being a teacher, for me, represents being capable of making the other become a better person"

Fica claro do excerto anterior que a maneira como Joana vê professores não é necessariamente a maneira que ela se vê. Diferentemente, em outro excerto Joana se implica, por meio do uso de dêitico de pessoa, para explicar como ela se vê como professora:

"When I go to school I feel that I have the responsibility of teaching them values and NOT ONLY the English language."

Nesse mesmo excerto, Joana usa o operador argumentativo not only para indicar restrição com relação ao papel do professor de língua inglesa. Além do mais, para destacar ainda mais a importância de tal operador Joana utiliza o recurso gráfico de caixa alta de modo a chamar atenção para a restrição que estabelece.

Joana continua a se implicar para mostrar como sê vê para descrever de que forma ela entende o professor que tem a responsabilidade de ensinar não somente a língua inglesa:

"Specially because I'm trying to implement a new way of teaching English which is totally different from what I've learned thoughout my life"

Ela modaliza seu enunciado ao fazer uso de specially e intensifica a diferença entre ensinar só inglês x ensinar mais que inglês e faz uso da conjunção because para explicar seu ponto de vista. Ao não se ver como professora, Joana deixa claro que o professor genérico descrito por ela é somente uma utopia.

"It looks like and utopy. But in fact, it's just a dream. A dream that may be possible to become true."

Por meio do operador argumentativo but a aluna-professora contrapõe realidade $x$ sonho. Joana também faz uso da modalização deôntica may para indicar sua opinião baseada nos valores do mundo social sobre o conteúdo temático "poder tornar-se real".

Nesse sentido, acreditamos que Joana usa sua ação verbal no blog para validar representações sobre ser professor e consolidar seu self de que não quer ser professora em função do descompasso realidade e utopia. Ao escrever sua postagem, Joana coloca em embate vozes da academia e do ensino público, e tenta produzir novos sentidos acerca dessa relação. Isso revela o papel do blog como ferramenta para (re)construção identitária por meio do uso da argumentação.

A última produção analisada é da aluna-professora Libela. Ela faz o uso da sequência descritiva para enumerar as características de como ela se vê como professora.

ANCORAGEM: Quem sou como professor

ASPECTUALIZAÇÃO: diferentes formas de se ver como professor

ASPECTUALIZAÇÃO: visão romântica da educação e mudança da realidade

RELACIONAMENTO: ensinar não só inglês para os alunos e aprender, como professor, ser melhor

De todas elas é a única que já se vê como professora. Tal característica é explicada por sua própria vivência. Libela já foi professora antes de entrar no curso de Letras. $\mathrm{O}$ foco da postagem dela é questionar que identidade profissional ela defende. Para tanto, ela faz uso de frases interrogativas de cunho retórico. Libela não deseja realmente que seu interlocutor responda tais questões. As frases interrogativas, usadas por ela, são um recurso argumentativo para direcionar o modo como ela se vê profissionalmente.

"It is not an easy question to be answered, however it is a relevant thing to question ourselves, I mean, do we know who we are and what are our objectives as a teacher? Are we everyday in the classroom just to do our jobs and go home after that? Or, do we believe that something has to be done and we might be the work force to do that?"

Além de estar constantemente implicada na postagem, Libela enfatiza sua identidade profissional enquanto professora para transformação social conforme no seguinte excerto: 
"I won't give up on trying my best to improve my teaching, not only in terms of didatic and linguistic aspects, but most of all in trying to teach these children how to be a better citizen, a better son, a better student...while I learn myself how to be a better me."

Libela faz uso do operador argumentativo que indica restrição not only para indicar um contra-argumento do que ela considera não ser sua identidade profissional. Nesse mesmo excerto, a aluna-professora faz uso do operador argumentativo but para colocar em interface as oposições professora apolítica x professora política.

A postagem de Libela indica que a aluna-professora se utiliza do saber-dizer propiciado pelo blog para consolidar seu self, ao mesmo tempo em que, argumenta no sentido defender uma determinada posição social do que ela acredita ser o papel do professor.

\section{CONSIDERAÇÕES FINAIS}

Procuramos, nesse trabalho, analisar os efeitos argumentativos na produção de uma postagem de blog por alunas-professoras do curso de Letras Estrangeiras Modernas - Inglês. Defendemos a linguagem como instrumento regulador do psiquismo humano, conforme Vygostki, e articulamos o conceito de linguagem como agir, no quadro do interacionismo sociodiscursivo, com a argumentação.

As análises revelaram um processo de validação e consolidação do self das alunas-professoras, por meio da apropriação das práticas de uso do blog, desenvolvido a partir de um movimento argumentativo que dá índices da (re)constituição identitária posta em curso pela intervenção feita.

Acreditamos, pois, que a linguagem como dotada de persuasão pode ser incorporada aos estudos do interacionismo sociodiscursivo e fornecer outras significações sobre o papel da linguagem na morfogênese das ações, como defendido por Bronckart (2008).

No que diz respeito à educação de professores de línguas, reiteramos o papel dos gêneros de textos do meio digital, nesse caso o blog, na desestabilização de representações do aluno-professor e encadeamento de um processo de novos olhares para experiências antigas.

Esperamos dessa forma, por meio da apresentação de outra alternativa, ter contribuído para educação de professores comprometidos com seu desenvolvimento profissional, ao mesmo tempo, mais conscientes de seu papel na sociedade enquanto agentes de transformação social.

\section{REFERÊNCIAS}

AZEVEDO, M.C.H.; OLIVEIRA, E.G. Mecanismos intensificadores no discurso publicitário. Entretextos, v.5, p.09-20, 2005.

BAKHTIN, M. Os gêneros do discurso. In: Estética da criação verbal. Tradução de Maria Ermantina Galvão Gomes Pereira. São Paulo: Martins Fontes, 1992. p. 279-326.

BRONCKART, J. P. Atividade de linguagem, textos e discursos: por um interacionismo sócio-discursivo. Tradução de Anna Rachel Machado e Péricles Cunha. São Paulo: EDUC, 2003.

. Atividade de linguagem, discurso e desenvolvimento humano. Campinas: Mercado de Letras, 2006.

. O agir nos discursos: das concepções teóricas às concepções dos trabalhadores. Tradução de Anna Rachel Machado e Maria de Lourdes Meirelles Matêncio. Campinas: Mercado de Letras, 2008.

KOCH, I.V. A inter-ação pela linguagem. 3. ed. São Paulo: Contexto, 1997.

LEITÃO, S. The potential of argument in knowledge building. Human Development, n. 43, p. 332-360, 2000.

. Argumentação e desenvolvimento do pensamento reflexivo. Psicologia: reflexão e crítica, v. 20, n. 3, p. 454-462, 2007.

LIBERALI, F. C. Creative chain in the process of becoming a totality. Bakhtiniana, v.1, n.2, p.100-124, 2009. 
MATENCIO, M.L.M. Gêneros discursivos na formação de professores: reflexões sobre a construção de saberes e o processo de letramento. In: GIL, G.; VIEIRA-ABRAHÃO, M.H. Educação de professores de línguas: os desafios do formador. Campinas: Pontes Editores, 2008, p. 189-199.

MILLER, C.R.; SHEPHERD, D. Blogar como ação social: uma análise do gênero weblog. In: DIONISIO, A.P.; HOGGNAGEL, J.C (Orgs.). Estudos sobre gênero textual, agência e tecnologia. Recife: Ed. Universitária da UFPE, 2009. p. 61-92.

OLIVEIRA, E.G. A argumentação na Antiguidade. Signum, n.5, p. 213-225, 2002.

. Aspectos diferenciais dos operadores argumentativos e dos marcadores discursivos. In: MACEDO, J.; ROCHA, M.J.C.; NETO, J.A.S. Discursos em análises. Salvador: Universidade Católica de Salvador, Instituto de Letras, 2003. p. 231-243.

A argumentação: da Idade Média ao Século XX. Signum, v. 7, n. 2, p. 109-131, 2004.

VIGOTSKI, L.S. Pensamento e linguagem. São Paulo: Martins Fontes, 2. ed. Tradução de Jefferson Luiz Camargo, 1998.

Recebido em 14/11/12. Aprovado em 10/12/12. 